\title{
A STUDY OF TAIPEI OZONE PROBLEM
}

\author{
Chung-Ming Liu \\ Dept. of Atmospheric Sciences, National Taiwan University, Taipei, Taiwan, Republic of China \\ ShaW C. LIU \\ The Aeronomy Laboratory, NOAA/ERL, Boulder, CO, U.S.A.
}

and

SHIH-Hong Shen

The Environmental Protection Administration, Executive Yuen, Taipei, Taiwan, Republic of China

(First received 1 November 1988 and received for publication 22 August 1989)

\begin{abstract}
A high level of ozone has been a serious problem in Taipei. At one station there were concentrations of hourly $\mathrm{O}_{3} 127$ and 60 times $>120 \mathrm{ppbv}$ in 1986 and 1987 , respectively. The diurnal $\mathrm{O}_{3}$ variation is mainly governed by a single-peaked (SP) pattern with a major peak near noontime, and a double-peaked (DP) pattern with a primary peak near noontime and a secondary peak in the early morning. The analyses of observed $\mathrm{NO}_{x}, \mathrm{NO}_{2}$ and $\mathrm{NMHC}$ distributions suggest that the photochemical production of ozone is responsible for the primary peak but not the secondary peak. In January, DP occurs more frequently than SP, while in June the SP pattern dominates. Analyses of the surface meteorological data suggest that a unique localized circulation may be responsible for the occurrence of the secondary peak of the DP pattern. A simplified quasi-three-dimensional model is developed to analyze the effect of land-sea breeze on the temporal and spatial variation of $\mathrm{O}_{3}$.
\end{abstract}

Key word index:Urban ozone, land-sea breeze, nocturnal ozone peak.

\section{INTRODUCTION}

Taipei is the largest city in Taiwan. It is located in a basin (Fig. 1) with a population of about three million. Because of congested traffic and poor ventilation, air pollution is a major environmental problem. With large emissions of NO and NMHC and a subtropical environment, a substantial amount of $\mathrm{O}_{3}$ and other photochemical oxidants are expected to be produced.

In recent years, the Bureau of Environmental Protection of Taipei installed 14 air-quality monitoring stations (Fig. 1) to monitor the concentration of $\mathrm{CO}$, $\mathrm{SO}_{2}, \mathrm{NO}_{2}, \mathrm{NO}_{x}, \mathrm{NMHC}, \mathrm{O}_{3}$, etc. Based on the data available in 1986 and 1987, we have analyzed the characteristics of $\mathrm{O}_{3}$ distribution in Taipei. Because a secondary peak of $\mathrm{O}_{3}$, occurring just before daybreak, has been observed persistently over most stations, we tried to isolate the phenomenon from the rest of the data. Nocturnal $\mathrm{O}_{3}$ peaks have been observed previously by several groups (Kroening and Ney, 1962; Berry, 1964; Stasiuk and Coffey, 1974) and are usually interpreted to be a result of break-down of the nocturnal inversion layer (Samson, 1978; Mizuno and Yoshikado, 1983). In this study, a systematic analysis of meteorological parameters is undertaken to investigate the process responsible for the secondary peak.

Land-sea breeze along the river valley to the northwest is an important transport process, especially in summer, that governs the movement of pollutants in Taipei. A simplified quasi-three dimensional model is developed to simulate the effect of transport and photochemistry on the $\mathrm{O}_{3}$ build-up for a high ozone episode in summer.

\section{THE ANNUAL-MEAN STUDY}

After a preliminary inspection of the daily $\mathrm{O}_{3}$ data, we decided to separate the diurnal $\mathrm{O}_{3}$ variations into three types: a single-peaked (SP) type which has only a major peak near noon time; a double-peaked (DP) type which has both the major peak and a secondary peak occuring at night; and a low ozone (LO) type. Those days with the peak $\mathrm{O}_{3}$ between 10:00 and 16:00 at station I (which consistently has the highest $\mathrm{O}_{3}$ among the ten stations) $<40 \mathrm{ppbv}$, are classified as LO cases. The other days are classified as either DP or SP according to the occurrence of the nocturnal $\mathrm{O}_{3}$ peak. LO cases are ignored in this study. Table 1 lists the percentage of each type appearing in 1986 and 1987. The DP type occurs around $37 \%$ in both years, while the SP type occurs $22 \%$ and $32 \%$, respectively, in 1986 and 1987.

The data at the other nine stations are separated by using the same three groups of days as station I. In other words, station I is assumed to be representative 


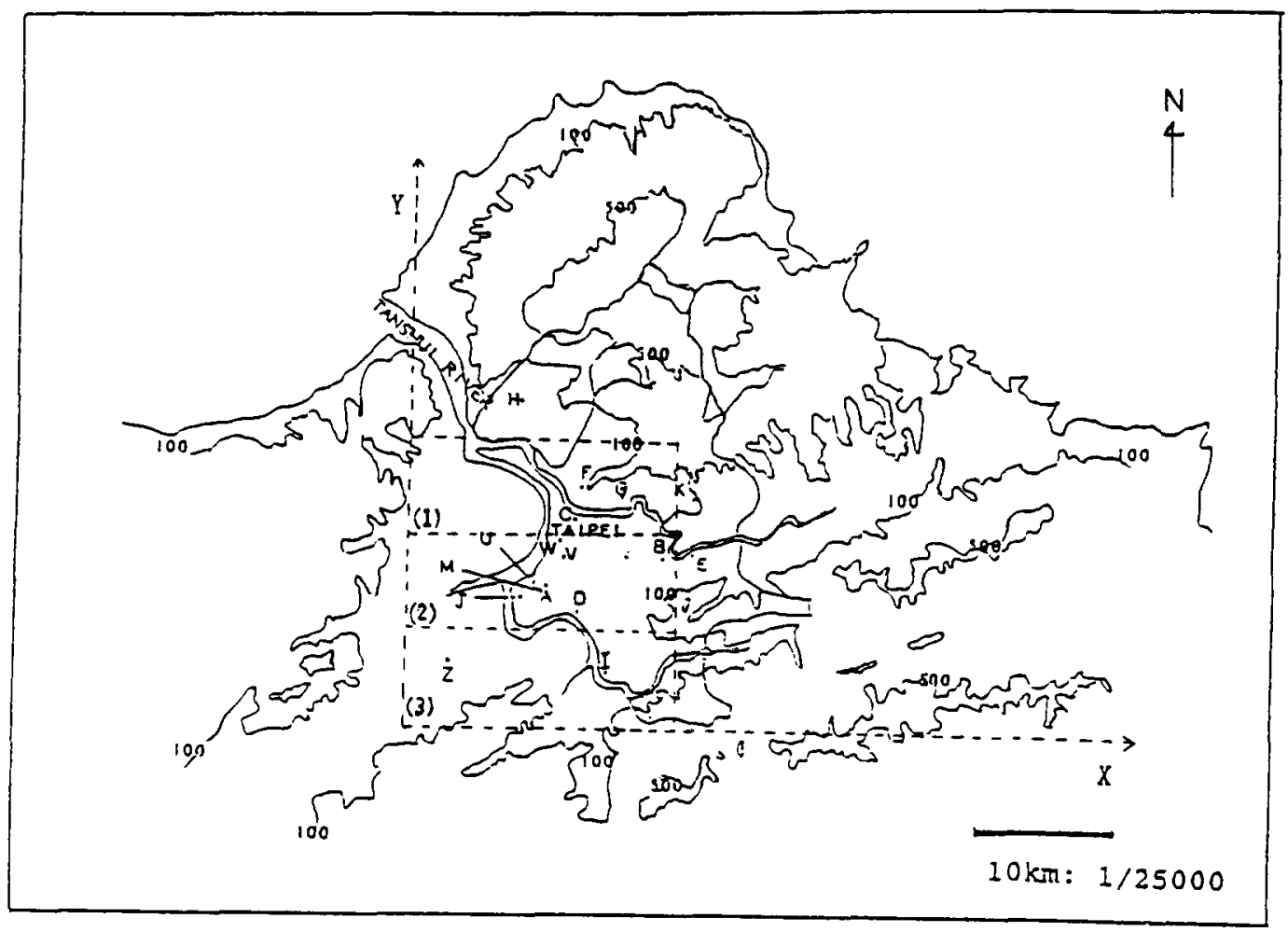

Fig. 1. The location of the air-quality stations in Taipei (marked by capital letters) monitored by the Bureau of the Environmental Protection of the Taipei City Government. Stations $\mathbf{M}$ and $\mathbf{Z}$ are the surface meteorological station and the vertical sounding station operated by the Central Weather Bureau. The contour lines of topography with height $100 \mathrm{~m}$ and $500 \mathrm{~m}$ are plotted. Three adjoining large grids are assumed to represent the northern, middle and southern sections of Taipei basin in the quasi-three-dimensional model.

Table 1. The percentage of the singlepeaked (SP), double-peaked (DP), and low ozone (LO) diurnal pattern occurring in 1986 and 1987

\begin{tabular}{rrrr}
\hline & SP(\%) & DP(\%) & LO(\%) \\
\hline 1986 & 22 & 37 & 41 \\
1987 & 32 & 38 & 30 \\
\hline
\end{tabular}

of all stations. This is an effective way to test the spatial correlation of the $\mathrm{O}_{3}$ distributions among the stations. A similar type of $\mathrm{O}_{3}$ distribution at all stations implies that the type of distribution is a widespread feature caused by a common process.

The annual mean of $\mathrm{O}_{3}$ at each station is plotted in Figs 2a and 2d, respectively, for 1986 and 1987 data. Highest $\mathrm{O}_{3}$ levels were observed at station I with a peak value of about $60 \mathrm{ppbv}$ near noontime. All stations exhibit a similar kind of diurnal pattern which consists of a major peak near noontime and a secondary peak in the early morning (around 5:00).

Figures $2 b$ and $2 c$ are the annual mean of SP and DP cases in 1986. The 1987 data are in Figs $2 \mathrm{e}$ and $2 \mathrm{f}$. At station I the noontime peak of SP mean in both years is around $90 \mathrm{ppbv}$. It is noted that before 8:00 and after 20:00, the annual mean SP ozone levels remain at consistently low value at all stations, suggesting that the SP pattern occurs at about the same time. The annual DP mean shows that the early morning peaks almost equal the noontime peaks. Again, all stations observe similar kind of diurnal variation pattern. The consistency among the stations is encouraging. It indicates that the method used to classify the $\mathrm{O}_{3}$ data is an effective one. More importantly, it suggests that the process which separates SP from DP is operative over all stations.

We have also analyzed other photochemically related gases. Figure 3 shows the 1987 annual mean, annual SP mean and DP mean of $\mathrm{NO}_{x}, \mathrm{NO}_{2}$ and NMHC. (The 1986 data are similar.) The diurnal variation of $\mathrm{NO}_{x}$ at most stations shows peaks around 9:00 and 22:00, which appear in both the SP and DP cases. On the other hand, $\mathrm{NO}_{2}$ has a peak at around 11:00 at all stations. The only discernible difference between SP and DP types is in the daytime distribution of $\mathrm{NO}_{2}$. The decrease of $\mathrm{NO}_{2}$ around noontime is obviously greater in the SP case than that in DP case, indicating higher photochemical activities in the former case converting $\mathrm{NO}_{2}$ to species such as $\mathrm{HNO}_{3}$ and PAN. This is consistent with the higher levels of $\mathrm{O}_{3}$ observed in the SP case as higher photochemical activities lead to greater production of $\mathrm{O}_{3}$. 


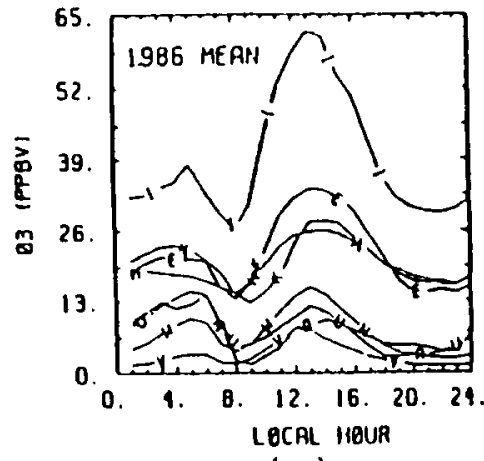

(a)

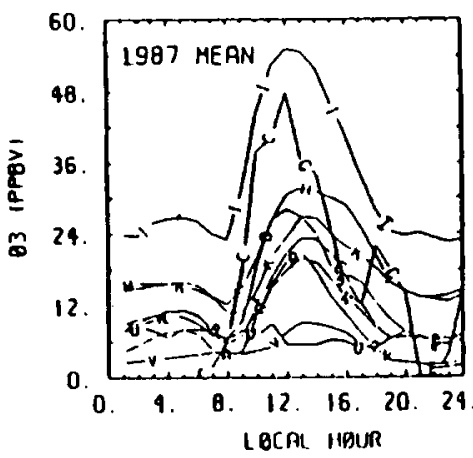

(d)

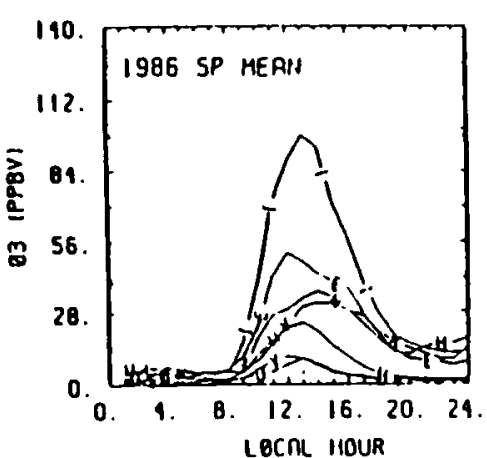

(b)

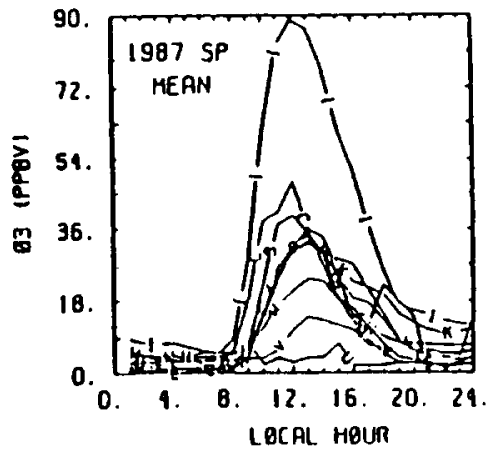

(e)

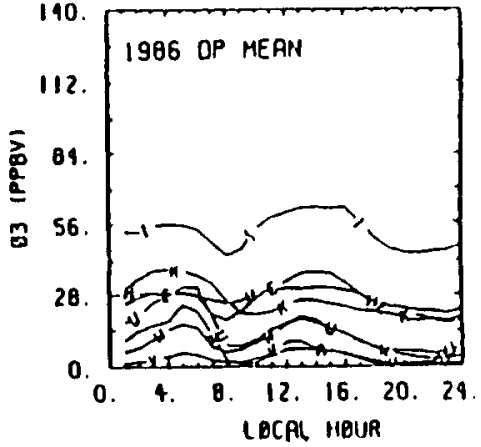

(c)

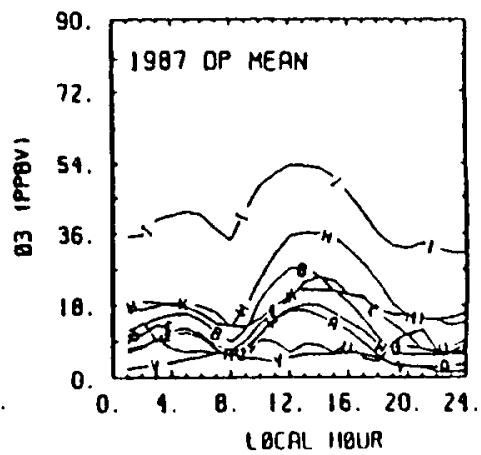

(f)

Fig. 2. Diurnal variation of $1986 \mathrm{O}_{3}$ concentration of (a) annual mean, (b) annual mean of SP- cases, and (c) annual mean of DP-cases. Similar figures for 1987 are shown in (d), (e) and (f). All station data are marked by a capital letter.

\section{THE SEASONAL EFFECT}

In order to examine the seasonal differences between the SP and DP types, we plot in Fig. 4 the 1987 data of the January and June monthly mean, monthly $\mathrm{SP}$ mean and DP mean of $\mathrm{O}_{3}$. The most obvious feature in this figure is that while the DP case occurs frequently in January, the SP case dominates in June. This is also shown in Table 2 which lists the percentage of SP, DP and LO cases observed in January and June of 1986 and 1987. It is interesting to note that the percentage of LO case in January is much larger than that in June, reflecting lower photochemical activity.

The monthly mean of SP cases at station $I$ in January has peak $\mathrm{O}_{3}$ about $80 \mathrm{ppbv}$ which is lower than the 110 ppbv value in June. Furthermore, the DP mean plots show that the double-peaked pattern occurs at every station with station I having the highest $\mathrm{O}_{3}$ amount. In June, the major peak near noontime is significantly larger than the secondary peak, while in January the secondary peak is close to or occasionally even larger than the major peak.

\section{ANALYSIS OF SURFACE METEOROLOGICAL DATA}

In this section the characteristics of meteorological data such as cloud amount, wind direction and wind speed during the occurrence of SP or DP case are analyzed to study the role of meteorological processes. Figures 5, 6 and 7 plot the percentage of hourly cloud amount, wind direction and wind speed that occurred in different intervals in SP or DP cases of 1986 and 1987. The observation station (M) is located near the central section of the Taipei basin with its anemometer about $20 \mathrm{~m}$ above surface.

In Fig. 5, a high percentage of occurrence of hourly cloud amount during daytime lies in between 80 and $100 \%$ cloud cover. Before 12:00, the chance of having a large amount of cloud in the SP cases is lower than that in the DP cases. This must contribute to the higher photochemical activities in the SP case as suggested earlier. There is no observation of cloud amount during the night-time when the secondary peaks occur. Thus the observed cloud amount does not provide enough information to identify the cause of the secondary peaks in the DP case.

In Figs $6 a$ and $6 \mathrm{~b}$, the SP case tends to have a high percentage of occurrence of wind coming from the south in early morning with peak percentage at 5:00. Whereas, in the afternoon, there are two likely surface wind directions. One is coming from the northwest with maximum probability at 14:00. The other is coming from the east with maximum occurrence at 20:00. Both the 1986 and 1987 plots show similar 


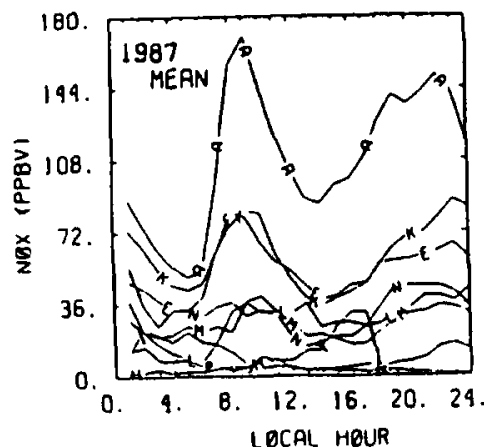

(a)

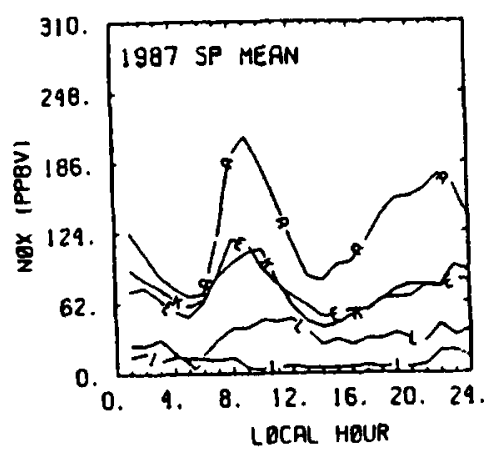

(b)

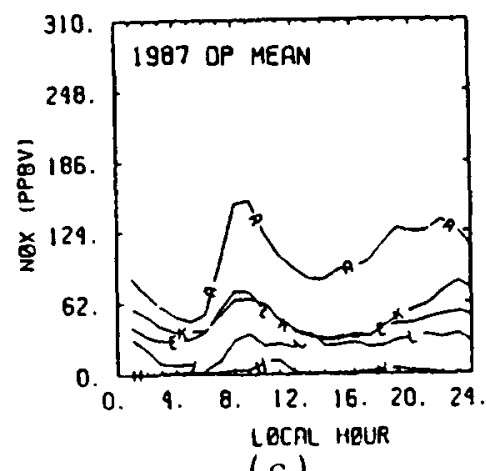

(c)

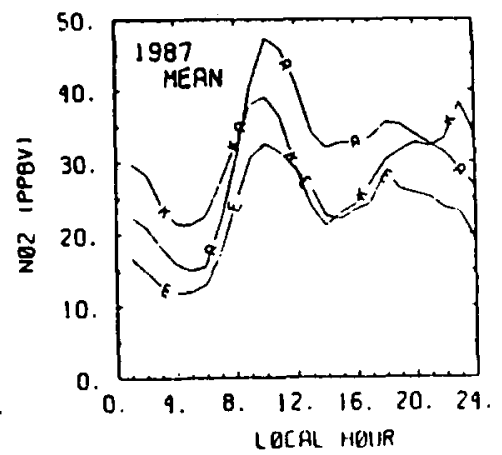

(d)

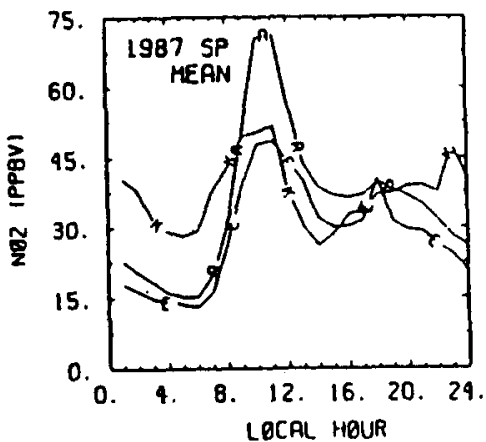

(e)

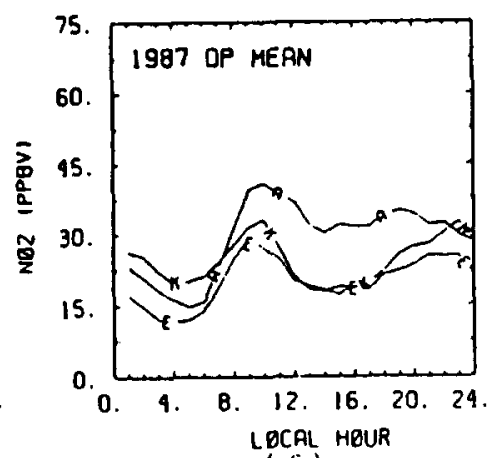

(f)

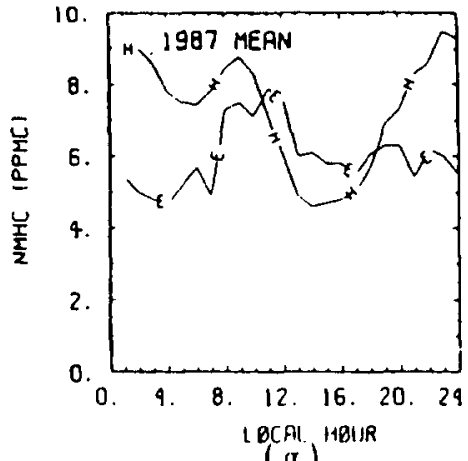

(g)

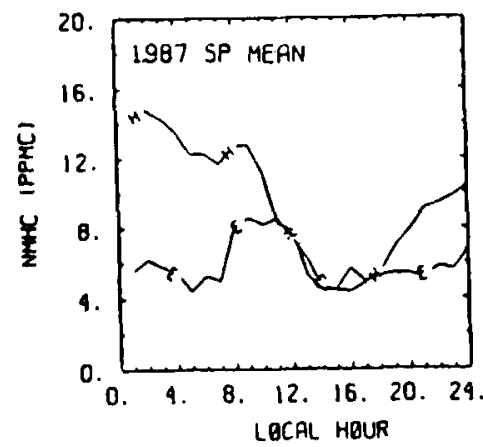

(h)

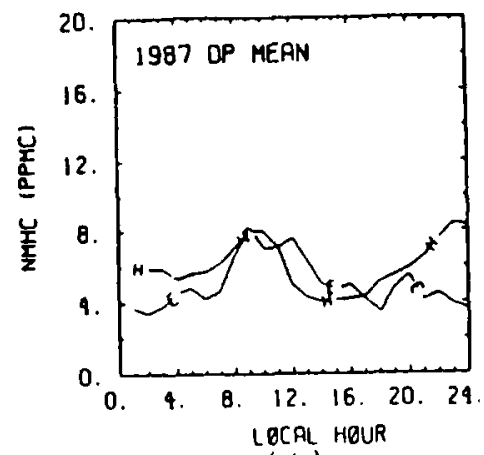

(i)

Fig. 3. Diurnal variation of the $1987 \mathrm{NO}_{x}$ concentration of (a) annual mean, (b) annual mean of SP-cases, and (c) annual mean of DP-cases. Similar figures for $\mathrm{NO}_{2}$ and $\mathrm{NMHC}$ are shown sequentially from (d) to (i). (All station data are marked by a capital letter.)

diurnal pattern. The early morning southerly wind can be related to the land breeze prevailing during the night, which is sometimes accompanied by the sea breeze at noontime coming from the northwest along the Tamshui river. The sea breeze blows pollutants from the central part of Taipei towards the southern edge of the city during the daytime. This is probably one of the major factors that contribute to the observed high $\mathrm{O}_{3}$ level at station $\mathrm{I}$. In the next section a simplified model is developed to evaluate the effect of horizontal transport in a case with a significant land sea breeze.

Figures $7 \mathrm{a}$ and $7 \mathrm{~b}$ show a high percentage of weak wind (with wind speed ranging from 0 to $1 \mathrm{~m} \mathrm{~s}^{-1}$ ) in the morning peaked at 10:00 in the SP cases of both years, which must be related to the change of wind direction shown in Figs $6 \mathrm{a}$ and $6 \mathrm{~b}$. The weak wind allows precursors of $\mathrm{O}_{3}$ to react locally after the morning traffic peak and to build-up high levels of $\mathrm{O}_{3}$. However, after 12:00 the wind speed increases to $3 \mathrm{~m} \mathrm{~s}^{-1}$ which tends to dilute pollutants in Taipei and to stop the build-up of $\mathrm{O}_{3}$. The observed $\mathrm{O}_{3}$ level on the average peaks before 14:00.

For the DP cases, Figs 6c and 6d show that the ENE-E winds dominate the whole day with peak percentage of occurrence at 5:00 and 13:00 which correspond to the peak times of the major and secondary $\mathrm{O}_{3}$ peaks. The cause of the surface northeasterly is 


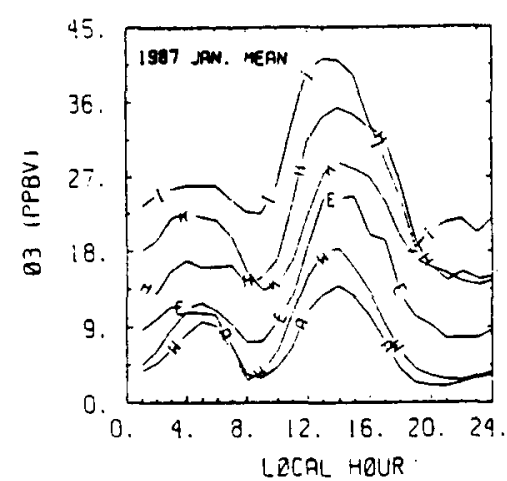

(a)

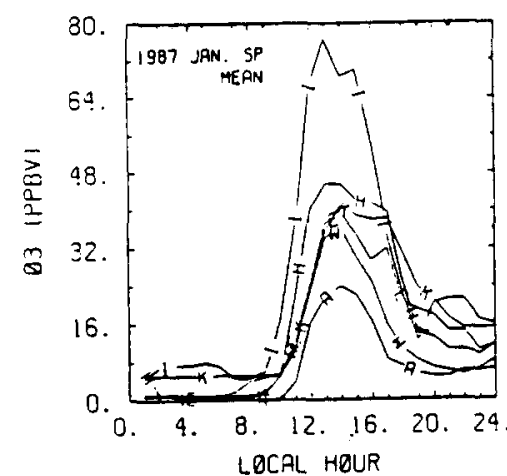

(b)

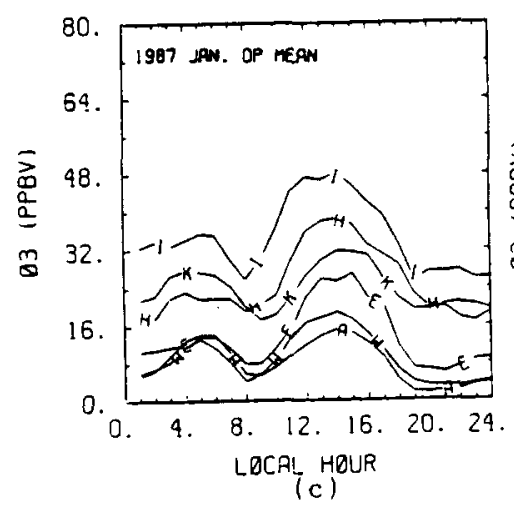

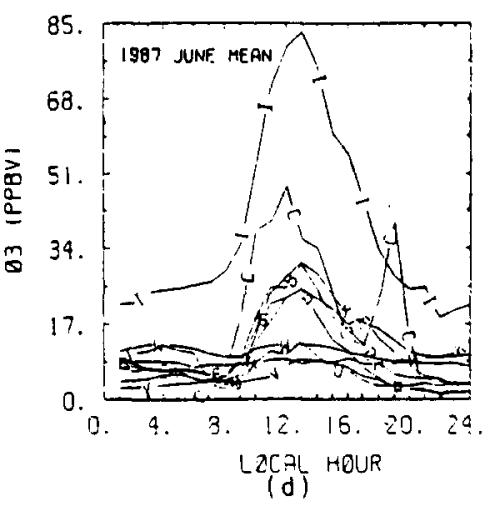

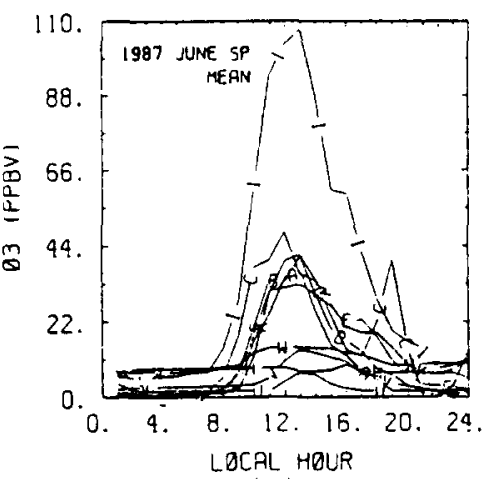

(e)

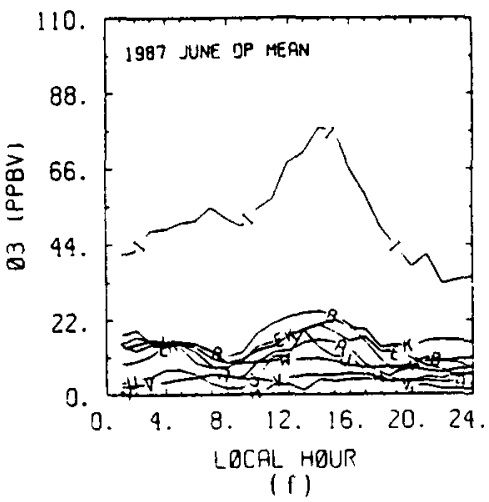

Fig. 4. Diurnal variation of the 1987 January $\mathrm{O}_{3}$ concentration of (a) monthly mean, (b) monthly mean of SP cases, and (c) monthly mean of DP-cases. Similar figures for June are shown in (d), (e) and (f). (All station data are marked by a capital letter.)

Table 2. The percentage of the single-peaked (SP), doublepeaked (DP), and low ozone (LO) diurnal pattern occurring in January and June of 1986 and 1987

\begin{tabular}{llrrr}
\hline & SP(\%) & DP(\%) & LO(\%) \\
\hline \multirow{2}{*}{1986} & January & 20 & 47 & 33 \\
& June & 64 & 21 & 15 \\
1987 & January & 16 & 45 & 39 \\
& June & 52 & 36 & 12 \\
\hline
\end{tabular}

probably related to a prevailing large-scale flow distorted by the topography around Taipei. The large scale flow is usually from the northeast and is a part of the high pressure system centered to the north of Taiwan (Tsay, 1987). According to Samson (1978) the nocturnal $\mathrm{O}_{3}$ maximum may be caused by vertical mixing of high concentrations of $\mathrm{O}_{3}$ aloft. We believe that the same mechanism contributes to the secondary peak. The northeasterly wind is associated with a descending motion or vertical mixing that brings down $\mathrm{O}_{3}$ aloft into the Taipei basin. The spatial variation of the secondary peaks is probably due to the variation of wind speed. Another likely cause is the spatial variation of $\mathrm{NO}$ emission which titrates $\mathrm{O}_{3}$ effectively at night. Systematic measurements of meteorological parameters and $\mathrm{NO}_{x}$ at the air quality 


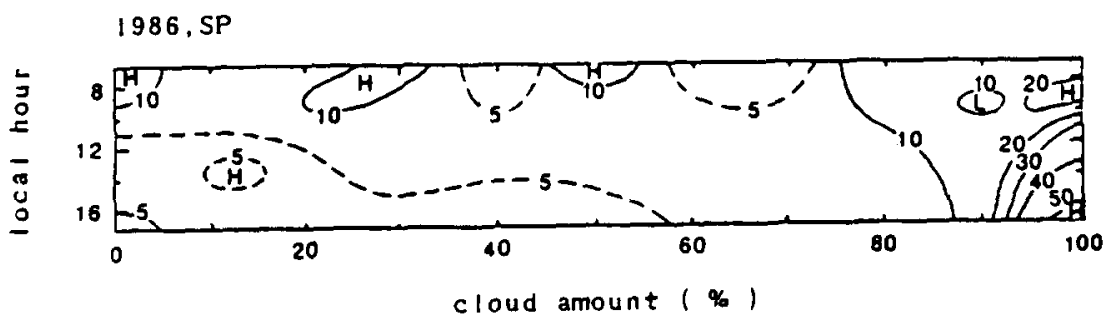

(a)

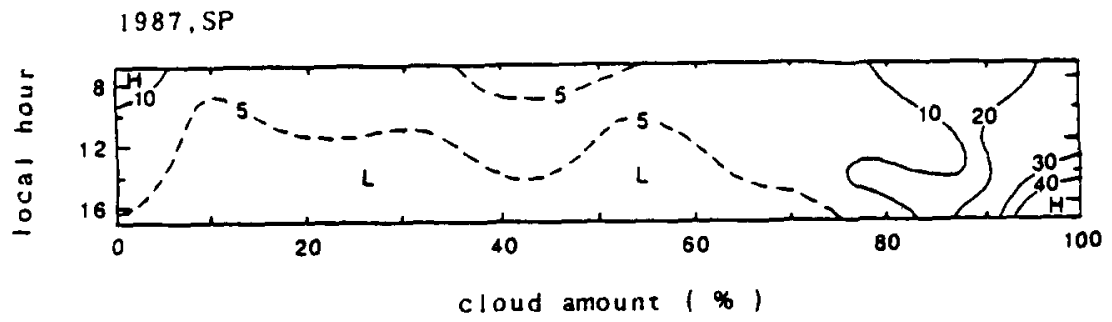

(b)

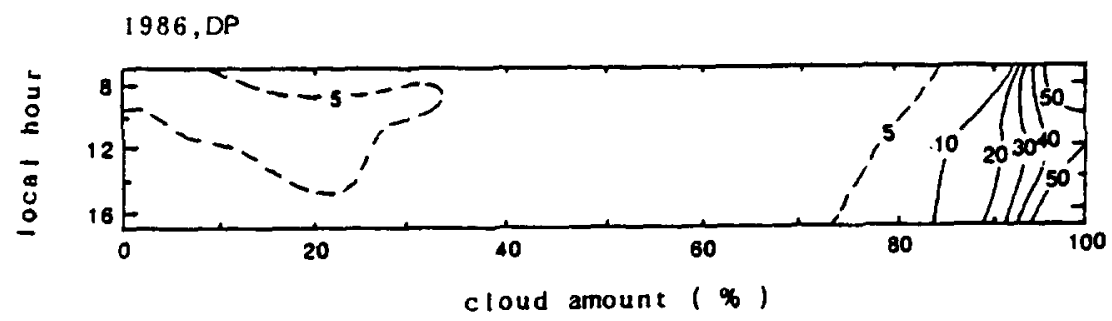

(c)

$1987, D P$

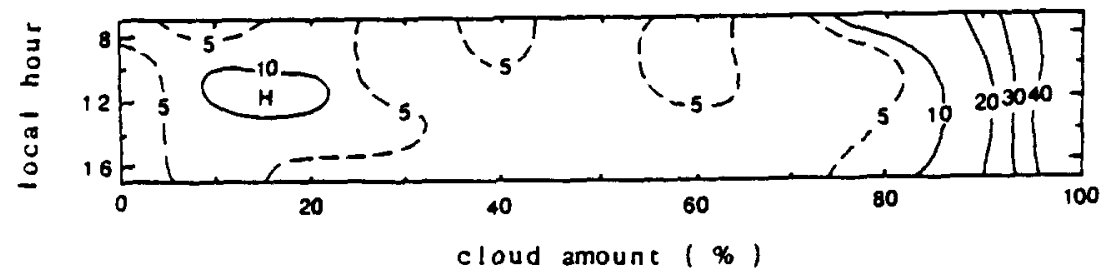

(d)

Fig. 5. The percentage of hourly cloud amount at station M, between 07.00 and 17.00 (local time) for the SP-cases in (a) 1986 and (b) 1987. Similar figures for DP-cases are shown in (c) and (d).

monitoring stations are needed to understand the exact process that contributes to the spatial variation of the secondary peaks.

Figures $7 c$ and $7 d$ show that in the DP cases the wind speed has a high likelihood of being greater than $1 \mathrm{~m} \mathrm{~s}^{-1}$ which is quite different from the high chance of low wind speed observed in the SP cases. The strong wind will increase vertical mixing as well as decrease the residence time of an air mass. As discussed earlier, increased vertical mixing will contribute to the secondary peak. On the other hand, the primary peak of the DP case will be suppressed relative to the SP case due to the decreased residence time that reduces the build-up of $\mathrm{O}_{3}$ from photochemical production.
The analyses of the surface wind data above are based on the annual SP and DP mean datasets. The results are also applicable to the summer and the winter cases individually, i.e. the difference between SP and DP is not a seasonal effect.

\section{MODEL SIMULATION}

On 12 June 1987, a typical single-peaked high $\mathrm{O}_{3}$ episode (Fig. 8a) was observed at station I with the peak value of $200 \mathrm{ppbv}$ for $2 \mathrm{~h}$ (12:00-14:00). Meanwhile, station $A$ recorded peak $\mathrm{O}_{3}$ of $100 \mathrm{ppbv}$ at 12:00. Surface wind observation near station A (Figs 
1986. SP

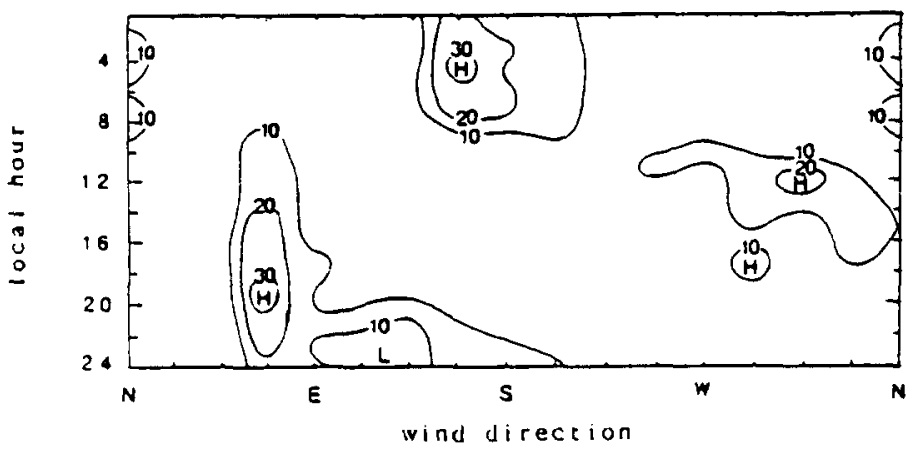

1987.SP

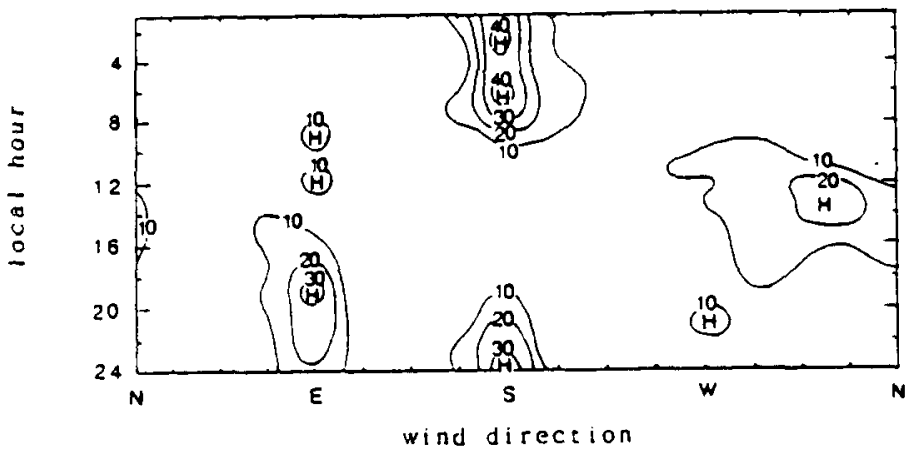

$1986, D P$

(b)

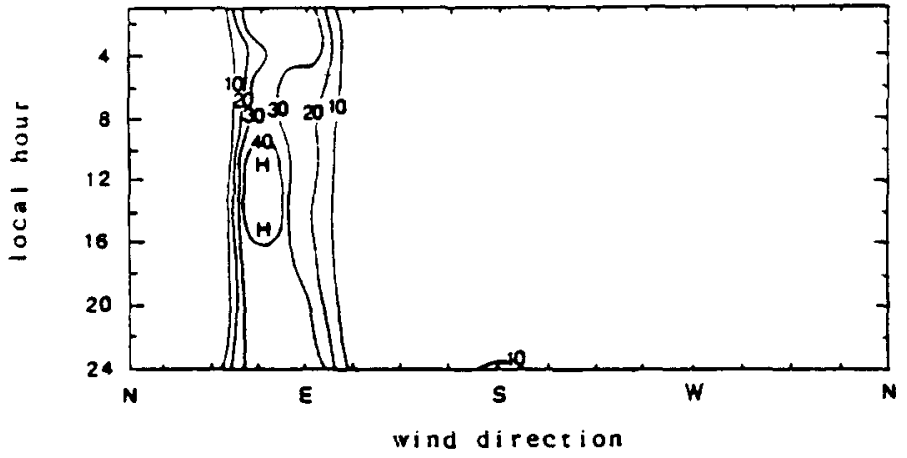

1987.DP

(c)

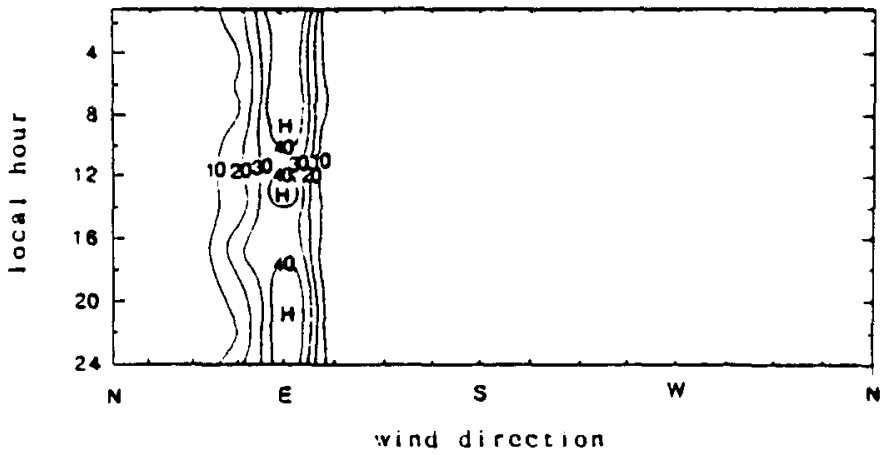

(a)

Fig. 6. The percentage of surface wind direction at station $\mathrm{M}$ in $24 \mathrm{~h}$ for the SP-cases in (a) 1986 and (b) 1987. Similar figures for surface wind direction for DP-cases are shown in (c) and (d). 


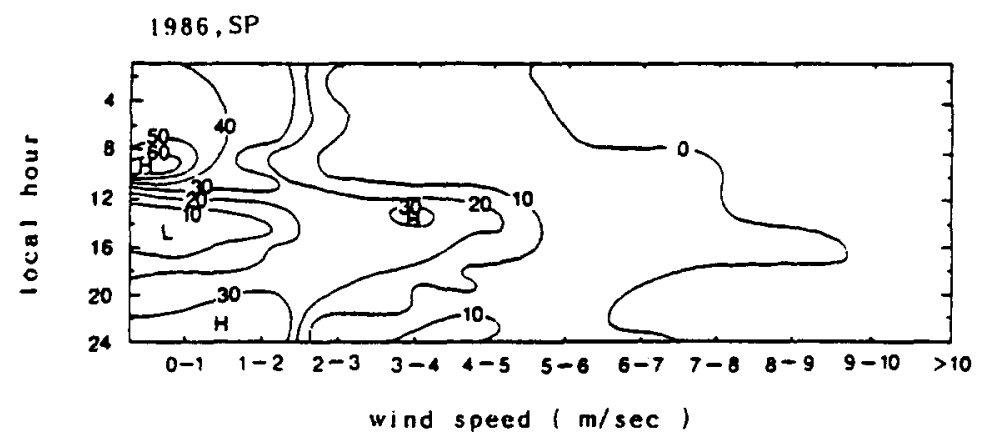

(a)

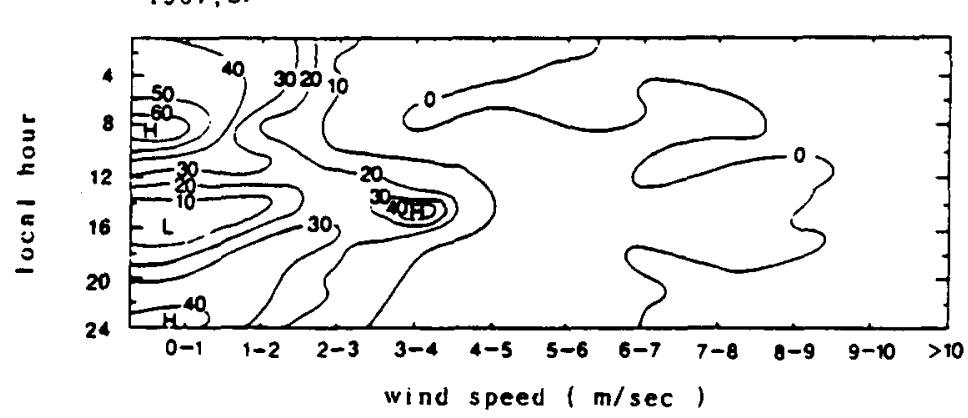

(b)

$1986 . D P$

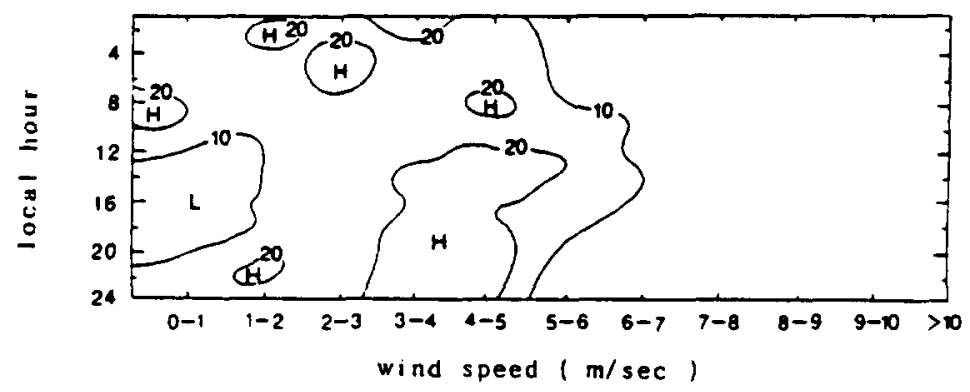

(c)

1987. DP

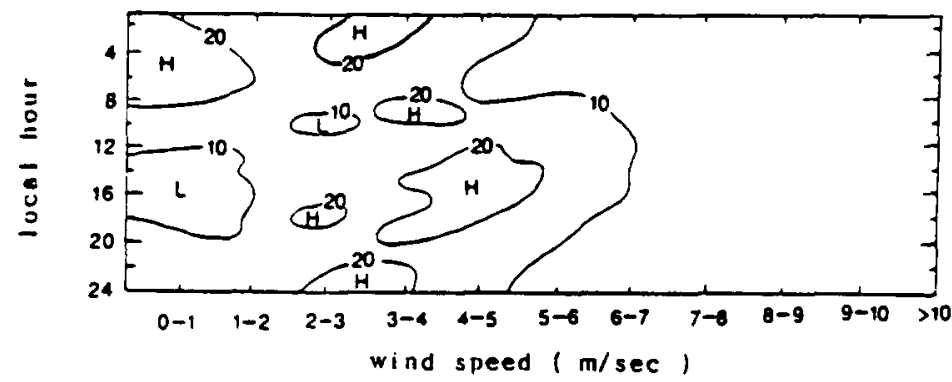

(a)

Fig. 7. The percentage of surface wind speed at station $M$ in $24 \mathrm{~h}$ for the SP. cases in (a) 1986 and (b) 1987. Similar figures for surface wind speed for DP-cases are shown in (c) and (d).

9a and $9 \mathrm{~b}$ ) showed clearly the signature of a typical land-sea breeze along the Tamshui river, which is southeasterly in the early morning and northwesterly in the afternoon.

In this section, a quasi-three-dimensional model is developed to study the role of horizontal advection in the spatial and temporal variation of $\mathrm{O}_{3}$ for that day. The Taipei metropolitan area is divided into three large grids $\left(20 \times 7 \mathrm{~km}^{2}\right)$ (Fig. 1) along the north-south direction ( $y$-axis), i.e. the northern (1), middle (2) and 

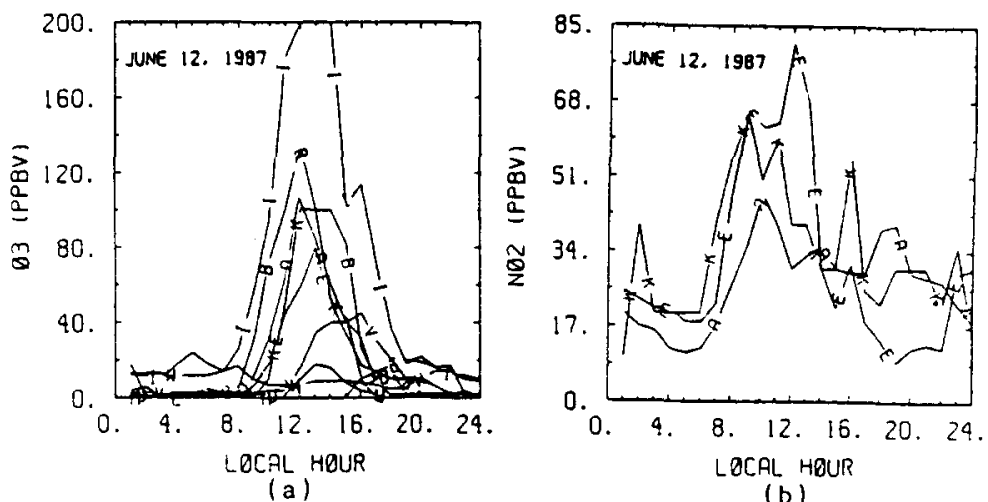

(b)
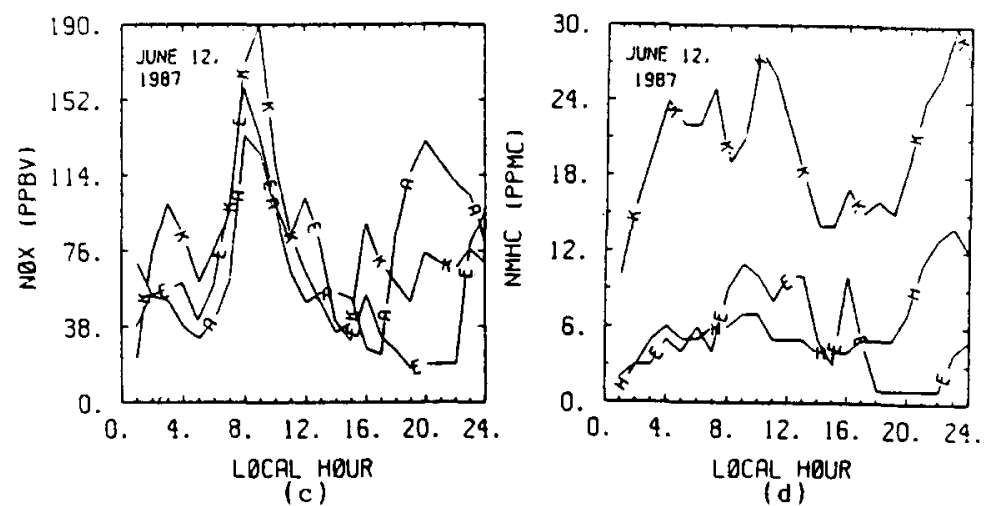

Fig. 8. The diurnal variation of (a) $\mathrm{O}_{3}$, (b) $\mathrm{NO}_{2}$, (c) $\mathrm{NO}_{x}$ and (d) $\mathrm{NMHC}$ on 12 June 1987.

southern (3) sections. Areas outside the three grids are assumed to have clean background air. Horizontal transport of pollutants is simulated by advection only, no turbulent diffusion is included. Wind fields are derived by interpolating values observed at meteorological stations.

Vertical transport of pollutants is simulated by diffusion. A one-dimensional photochemistry-diffusion model developed by Trainer et al. (1987) is adopted. The lowest $100 \mathrm{~m}$ of the model are divided into 10 layers with increasing spacing. Above $100 \mathrm{~m}$ an even spacing of $100 \mathrm{~m}$ is used for up to $6 \mathrm{~km}$. The continuity equation is solved by treating the transport part and the chemical part independently. A micrometeorological approximation is used to determine the height of the planetary boundary layer (PBL) (Fig. 9c) and the diffusion coefficients from the meteorological parameters supplied by the Blackadar PBL model (Blackadar, 1979; Zhang and Anthes, 1982) with the initial input of the vertical sounding data at station $Z$ (Fig. 1). The transport tendencies are solved by the method developed by Smolarkiewicz (1983) with the time step of $30 \mathrm{~s}$. A standard reaction scheme is used to describe the $\mathrm{CH}_{4}, \mathrm{CO}, \mathrm{H}_{2} \mathrm{O}, \mathrm{O}_{3}$ and $\mathrm{NO}_{x}$ chemistry (Liu et al., 1980). The reaction rates are updated according to JPL (1987). The chemistry of alkanes up to propane is modeled using the reaction schemes proposed by Atkinson et al. (1982). In the model, the transport of trace gases with photochemical lifetimes longer than $10 \mathrm{~min}$ is described by the continuity equation containing the horizontal advection terms along both $x$-axis (east-west) and $y$-axis (northsouth), the vertical diffusion term and the chemical production and loss terms. Species with a photochemical lifetime shorter than $10 \mathrm{~min}$, including all free radical species, are calculated by neglecting transport. The northern, middle and southern sections are estimated to contain about $5 \%, 65 \%$ and $35 \%$, respectively of total Taipei emissions of NO and NMHC based on the distribution of traffic. The diurnal variations of the emission of NO and NMHC are adjusted such that their distributions are consistent with observed values in Fig. 3. The anthropogenic emission of NMHC is assumed to have the composition the same as that used by a regional acid deposition model (ADMP, 1987).

Five different model scenarios are designed. Cases 1-4 are intended to evaluate the role of horizontal advection, while in case 5 we try to simulate observed $\mathrm{O}_{3}$ distribution. Case 1 allows no horizontal advection. Case 2 includes the $x$-axis advection term. Case 3 includes the $y$-axis advection term. Case 4 includes both the $x$-and $y$-axis advection terms. In these four cases, clean background air is assumed to be the initial distributions of chemical species.

Figure 10 compares the diurnal variation of $\mathrm{NO}_{x}$, 

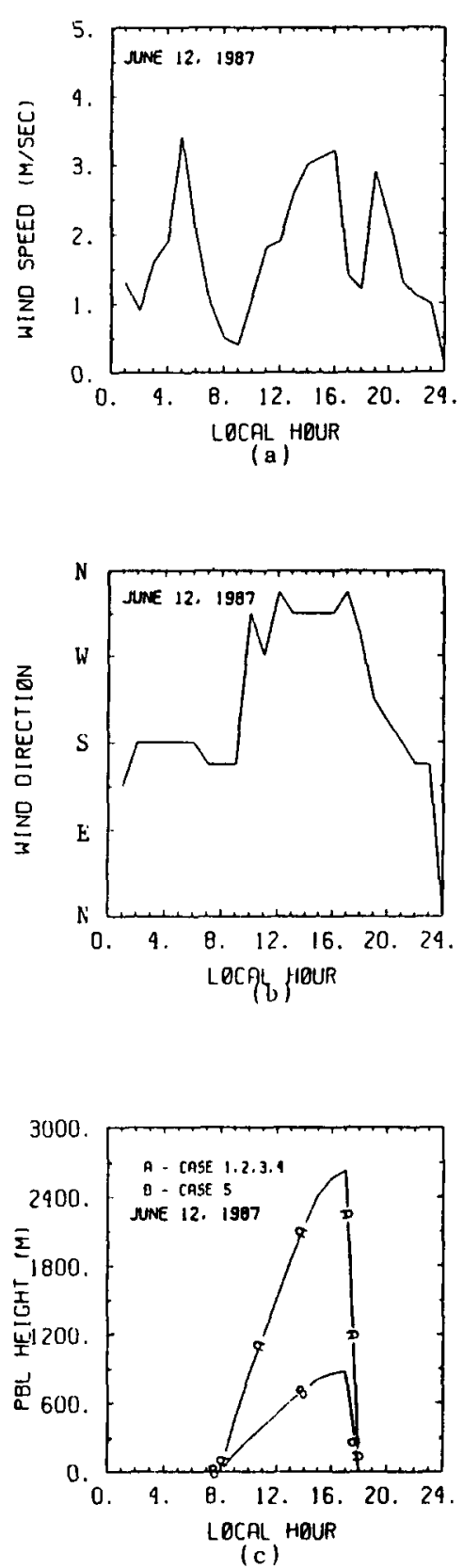

Fig. 9. The diurnal variation of surface wind (a) speed and (b) direction, and (c) the height of the planetary boundary layer (PBL) simulated by the Blackadar PBL model, on 12 June 1987.

NMHC and $\mathrm{O}_{3}$ calculated in the case 1-4 for the three adjoining boxes. In case 1 , no horizontal advection is allowed. $\mathrm{NO}_{x}$ and NMHC peak between 6:00 and 7:00 with maxima occurring in box 2 (middle section of Taipei) which is consistent with the distribution of $\mathrm{NO}$ and $\mathrm{NMHC}$ emissions. During the daytime, $\mathrm{O}_{3}$ increases steadily with the peak occurring at 16:00 prior to the drop of PBL height. The maximum $\mathrm{O}_{3}$ occurs in box 2 with 195 ppbv while box 1 and 3 peaks about $67.5 \mathrm{ppbv}$ and $136 \mathrm{ppbv}$, respectively. In case 2 (Figs $10 \mathrm{~d}, \mathrm{e}, \mathrm{f}$ ) the advection along the $x$-axis is included. The horizontal wind dilutes $\mathrm{NO}_{x}$ and $\mathrm{NMHC}$ significantly and slows the build-up of $\mathrm{O}_{3}$. Also, the peak time of $\mathrm{O}_{3}$ is after $16: 00$ of case 1 to $11: 00-12: 00$ in both box 2 and 3, with peak values of 80 and 70 ppbv, respectively. In case 3 (Figs $10 \mathrm{~g}, \mathrm{~h}, \mathrm{i}$ ), the advection along the $y$-axis is considered. The $\mathrm{O}_{3}$ peak amount in box 2 (occurring at 16:00) is $144 \mathrm{ppbv}$, while that in box 1 and 3 is increased to 100 and $161 \mathrm{ppbv}$, respectively. These results suggest that the emitted $\mathrm{NO}_{x}$ and NMHC in box 2 is transported to box 1 in the early morning (Fig. 9b) and to box 3 at noon-time, resulting in increased photochemical production of $\mathrm{O}_{3}$ in both box 1 and 3 . In case 4 (Figs $10 \mathrm{j}, \mathrm{k}, 1)$, the advection along both $x$ - and $y$-axes is considered. The effect of advection along the $x$-axis clearly forces the build-up of $\mathrm{O}_{3}$ to stop at around 12:00 and hence the peak $\mathrm{O}_{3}$ is lowered. Meanwhile, the advection along the $y$-axis results in the peak $\mathrm{O}_{3}$ in box 3 being 80 ppbv which is higher than that in box 2 (68 ppbv).

In the 1-4 cases, the simulated results do not agree with the observed value (Fig. 8). It is argued that the PBL height calculated by the Blackadar PBL model may not be applicable for the case of the marine air moving inland during the daytime. Hence, in case 5 the PBL height is lowered by $2 / 3$ (Fig. 9c) with the rest the same as case 4 . The results (Figs $10 \mathrm{~m}-10 \mathrm{o}$ ) show that the peak $\mathrm{O}_{3}$ at $12: 00$ in box 1,2 and 3 is 40,140 and $210 \mathrm{ppbv}$, respectively, which corresponds closely to the observed spatial variation pattern (Fig. 8a) with stations $\mathrm{H}, \mathrm{A}$ and $\mathrm{I}$ being taken as the representative station of the northern, middle and southern sections of Taipei. In addition, the peak $\mathrm{NO}_{x}$ occurring at 6:00 in box 2 is about $128 \mathrm{ppb}$ which is consistent with the 135 ppbv observed at station $A$.

\section{SUMMARY AND DISCUSSION}

In this paper, analysis of the observed $\mathrm{O}_{3}$ data in Taipei shows that there is 127 and 60 occurrences of hourly $\mathrm{O}_{3}>120 \mathrm{ppbv}$ in 1986 and 1987 , respectively, occurring at the southern rim of Taipei. There are also about 25 occurrences of hourly $\mathrm{O}_{3}>200$ ppbv in each year.

The annual mean $\mathrm{O}_{3}$ level at the stations shows a primary peak near noontime and a secondary peak in the early morning. In both years, the primary peak $\mathrm{O}_{3}$ is much larger than the secondary peak. We have separated the diurnal $\mathrm{O}_{3}$ distributions into three types: the SP- type with only the major peak, the DP. type with both the major and secondary peaks, and the rest being taken as the low $\mathrm{O}_{3}$ (LO) type.

The annual mean of SP and DP cases indicates that the stations in Taipei have similar diurnal distribu- 
tions. Station I which is at the southern rim of Taipei consistently has the highest $\mathrm{O}_{3}$ level. The percentage of occurrence of the DP cases is slightly greater than that of the SP cases in both years. In January, the chance of having a diurnal DP pattern is higher than that of the SP pattern, whereas in June this is reversed. The analyses of the diurnal variation of $\mathrm{NO}_{x}, \mathrm{NO}_{2}$ and NMHC suggest that the photochemical production of $\mathrm{O}_{3}$ is the primary cause of the major peak at noontime, but not the secondary peak in the early morning.

Analysis of the surface meteorological data, including cloud amount, wind direction and wind speed, reveals that variation in the circulation over Taipei is responsible for the difference between the SP case and the DP case. For instance, the southerly land breeze in the early morning plays a minor role on $\mathrm{O}_{3}$ formation, but the stagnant conditions in the mid-morning prior to the change of wind direction are essential for the photochemical build-up of $\mathrm{O}_{3}$. The strong northwesterly in the afternoon limits the $\mathrm{O}_{3}$ build-up in the mid-section of the city while it pushes a large amount of $\mathrm{O}_{3}$ to the southern part of Taipei. These effects of the land-sea breeze are successfully simulated by a simplified quasi three-dimensional photochemistrydiffusion-transport model.

When northeasterly winds prevail, upper level $\mathrm{O}_{3}$ is brought downward into the basin after passing through mountains at the northeastern side of Taipei. We believe that this process is responsible for the secondary $\mathrm{O}_{3}$ peak. Such an event occurs simultaneously at all stations. This is consistent with the fact that the northeasterly wind is strong and persistent for a long period. However, there is substantial spatial variation in the magnitude of the secondary peaks among the stations. We think that the variation is probably caused by the difference in the NO emissions near the station.

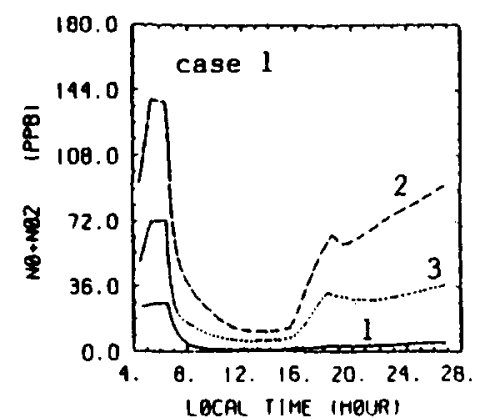

(a)

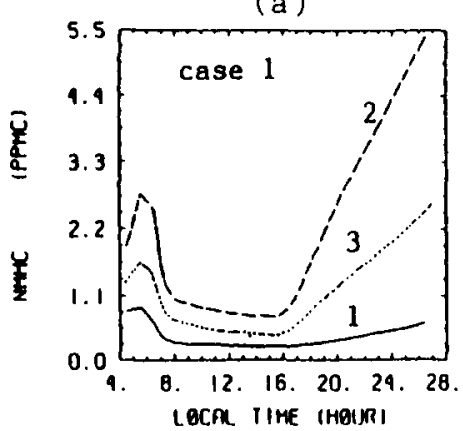

(b)

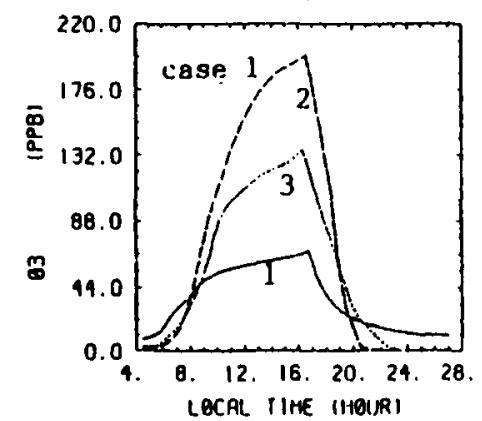

(c)

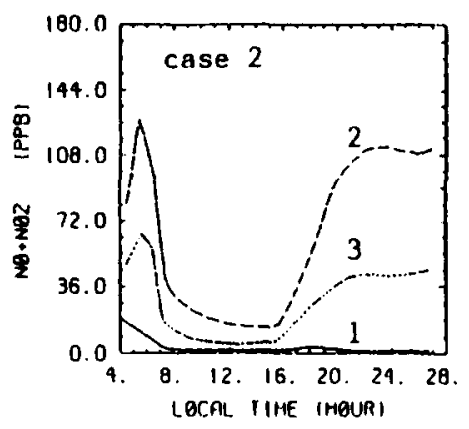

(d)

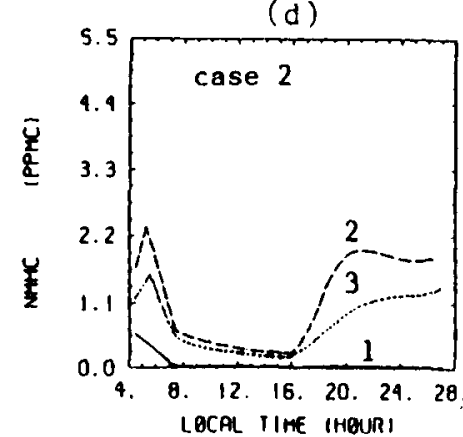

(e)

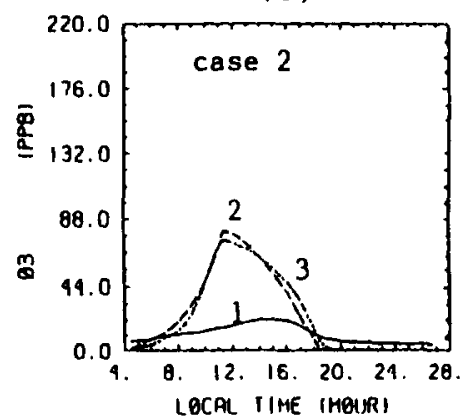

(f)

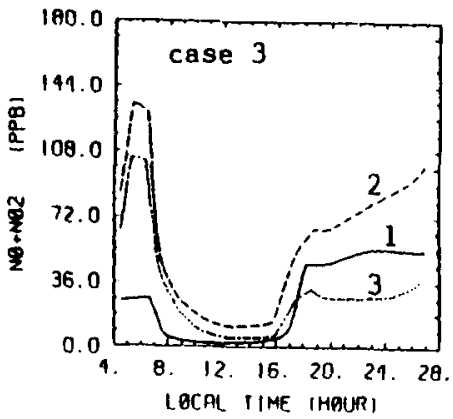

(g)

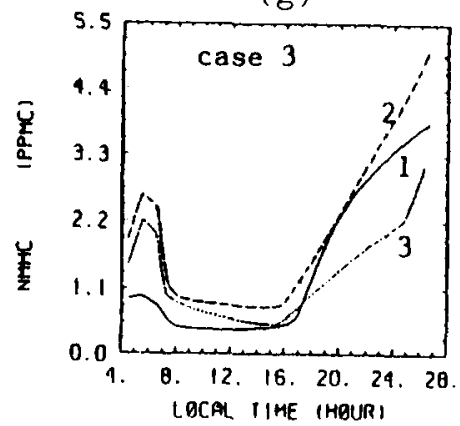

(h)

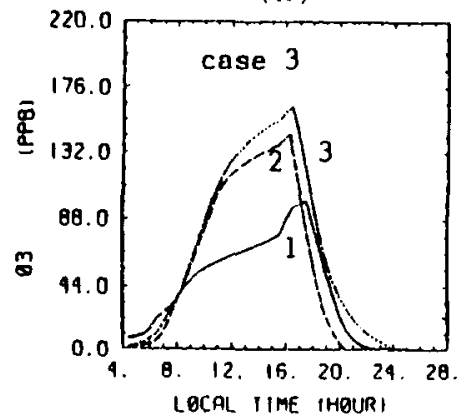

(i)

Fig. 10 (a)-(i). 


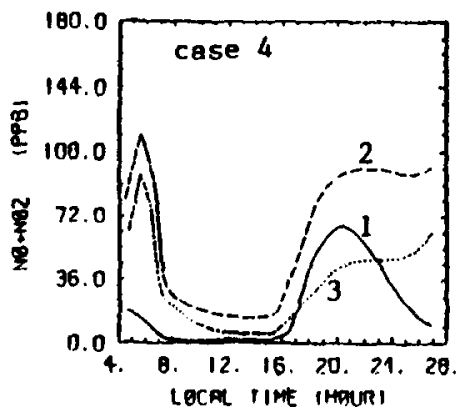

(j)

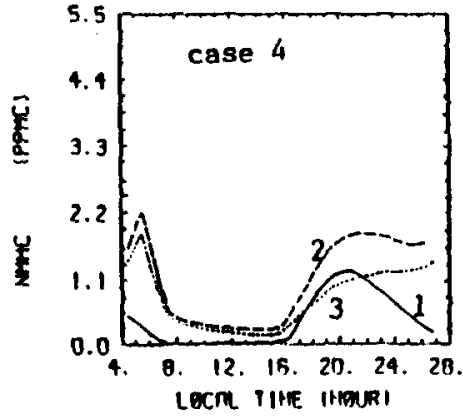

(k)

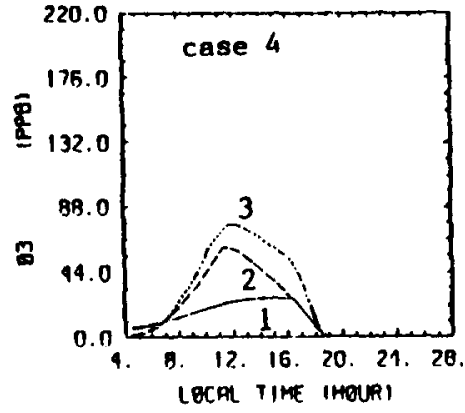

(1)

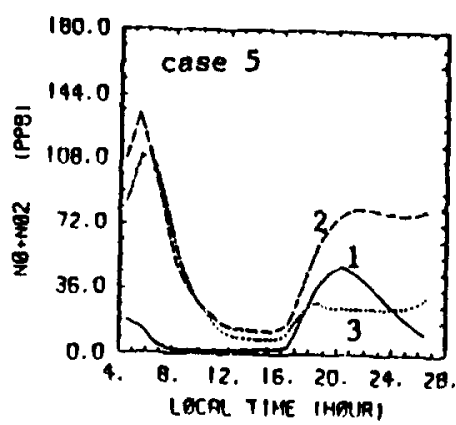

(m)

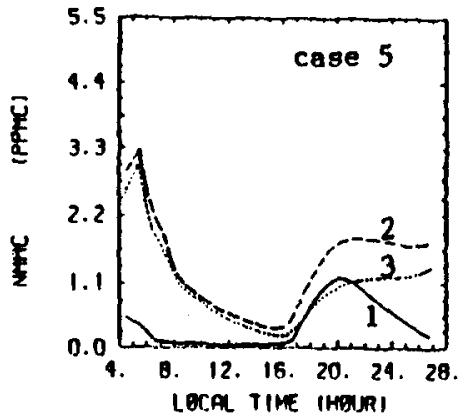

(n)

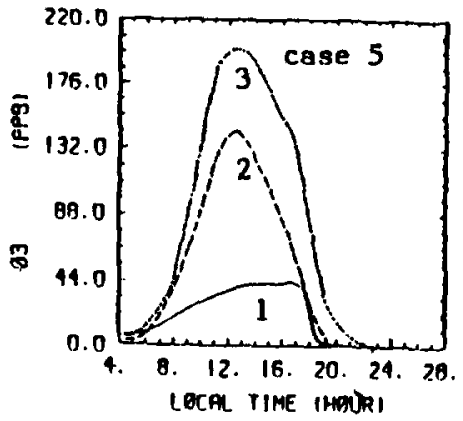

(o)

Fig. 10. The hourly variation of (a) $\mathrm{NO}_{x}$, (b) $\mathrm{NMHC}$ and (c) $\mathrm{O}_{3}$ at $5 \mathrm{~m}$ height of boxes 1,2 and 3 , resulted from the case 1 study. Similar figures are shown sequentially for cases 2-5. (Boxes 1, 2 and 3 represent the northern, middle and southern section of Taipei, respectively.)

\section{REFERENCES}

ADMP (1987) Development and implementation of chemical mechanisms for the regional acid deposition model (RDAM).

Atkinson R., Lloyd A. C. and Winges L. (1982) An updated chemical mechanism for hydrocarbon/ $/ \mathrm{NO}_{x} / \mathrm{SO}_{2}$ photooxidations suitable for inclusion in atmospheric simulation models. Atmospheric Environment 16, 1341-1355.

Blackadar A. K. (1979) High resolution models of the planetary boundary layer. In Advances in Environmental Science and Engineering, Vol. 1 (edited by J. Pfafflin and E. Ziegler), pp. 50-85. Gordon and Breach, New York.

Environmental Protection Agency of the Republic of China, (1988) The evaluation of the air pollution control in 1987 at the Taiwan area.

Jet Propulsion Laboratory (JPL) (1987) Chemical kinetics and photochemical data for use in stratospheric modeling.

Kroening J. L. and Ney E. P. (1962) Atmospheric ozone. $J$. geophys. Res. 67, 1867-1875.
Liu S. C., Kley D., McFarland M., Mahlman J. D. and Levy H. II (1980) On the origin of tropospheric ozone. $J$. geophys. Res. 85, 7546-7552.

Mizuno T. and Yoshikado H. (1983) On some characteristics of the diurnal variation of $\mathrm{O}_{3}$ observed in island, urban and rural areas. Atmospheric Environment 17, 2575-2582

Samson P. J. (1978) Nocturnal ozone maxima. Atmospheric Environment 12, 951-953.

Smolarkiewicz P. K. (1983) A simple positive definite advection scheme with small implicit diffusion. Mon. Wea. Rev. 111, 479-486.

Trainer M., Hsie E. Y., McKeen S. A., Tallamraju R., Parrish D. D., Fehsenfeld F. C. and Liu S. C. (1987) Impact of natural hydrocarbons on hydroxyl and peroxyl radicals at a remote site. J. geophys. Res, 92, 11, 879-11,894.

Tsay C. Y. (1987) Northern Taiwan local circulation study. $J$. atmos. Sci. 15, 179-198.

Zhang D. and Anthes R. A. (1982) A high-resolution model of the planetary boundary layer-sensitivity tests and comparisons with SESAME-79 data. J. appl. Met. 21, 1594-1609. 